\title{
Porto Alegre e sua região metropolitana no contexto das contradições da metropolização brasileira contemporânea
}

PAULO ROBERTO RODRIGUES SOARES LUGIANO JOEL FEDOZZ"

\section{Resumo}

O artigo trata de Porto Alegre e sua Região Metropolitana no contexto dos atuais processos de urbanização e metropolização brasileiros. Primeiramente, relacionamos a metropolização de Porto Alegre com as transformações no processo de metropolização em nível mundial e na América Latina, mudanças essas advindas do processo mais amplo de mundialização do capital, no qual se destaca a economia dos serviços e a financeirização da economia e suas repercussões na produção imobiliária e urbana das principais metrópoles e cidades latino-americanas. A seguir, tratamos das especificidades do processo de metropolização de Porto Alegre e sua região metropolitana, abordando os impactos econômicos e sociais da transição de modelo de desenvolvimento do capitalismo brasileiro nos últimos 30 anos. Finalizando, analisamos os desafios para a gestão do espaço metropolitano à luz do Estatuto da Metrópole, recentemente promulgado, e das contradições políticas e sociais impostas pelo novo regime de acumulação urbano da metrópole.

Palavras-chave: Metropolização. Financeirização. Reestruturação Urbana. Gestão Metropolitana. Região Metropolitana de Porto Alegre (RMPA).

\footnotetext{
" Universidade Federal do Rio Grande do Sul (Brasil)

${ }^{* *}$ Universidade Federal do Rio Grande do Sul (Brasil)
} 


\title{
The Metropolitan Area of Porto Alegre in the context of the contradictions of Brazilian contemporary metropolization
}

\begin{abstract}
The paper focuses on the Metropolitan Area of Porto Alegre in the context of current Brazilian urbanization and metropolization processes. First, the metropolization of Porto Alegre is associated with the changes in the metropolization processes that take place worldwide and particularly in Latin America. These changes result from a wider process of internationalization of the capital, which emphasizes the service economy and financialization of the economy, and its impacts on real estate and urban production of Latin America major cities. Thereafter, the specificities of the metropolization process in Porto Alegre and its metropolitan area are discussed, addressing the economic and social impacts of the transition of Brazilian capitalist development model during the last 30 years. Finally, we analyze the challenges posed to the administration of metropolitan space in the light of both the "Statute of the Metropolis", a recently enacted Brazilian law on territorial organization of metropolitan regions, and the political and social contradictions imposed by the new urban regime of accumulation observed in the metropolis.
\end{abstract}

Key-words: Metropolization. Financialization. Urban Restructuring. Metropolitan Management. Porto Alegre Metropolitan Region. 


\section{Introdução}

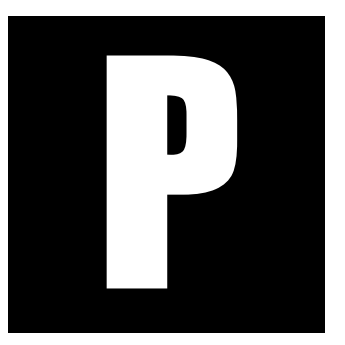

orto Alegre, a metrópole mais meridional do Brasil, é uma das principais metrópoles do país, estando inserida no processo de metropolização brasileiro desde o final dos anos 1960. Embora a cidade de Porto Alegre seja hoje a décima em população (IBGE, 2015), sua Região Metropolitana, com mais de quatro milhões de habitantes, é a quarta concentração econômica e urbana brasileira, após as regiões metropolitanas de São Paulo, Rio de Janeiro e Belo Horizonte. Essa situação resulta de uma especificidade do contexto metropolitano porto-alegrense: a presença de núcleos urbanos importantes, econômica e demograficamente, na região metropolitana.

Entretanto, o presente artigo não se restringe ao contexto demográfico e econômico em termos quantitativos. Nossa intenção é demonstrar a posição de Porto Alegre e de sua Região Metropolitana no atual contexto político e social dos processos de urbanização e metropolização no Brasil.

Para tal, primeiramente, precisamos relacionar a metropolização de Porto Alegre com as transformações no processo de metropolização em nível mundial e na América Latina, mudanças estas advindas do processo mais amplo de mundialização do capital, no qual se destaca a economia de serviços, a reestruturação industrial e a financeirização da economia, com suas repercussões na produção imobiliária e urbana das principais metrópoles e cidades latino-americanas.

A seguir, tratamos das especificidades do processo de metropolização de Porto Alegre e sua Região Metropolitana, abordando os impactos econômicos e sociais da transição de modelo de desenvolvimento do capitalismo brasileiro nos últimos trinta e cinco anos (1980-2015). Esta transição, igualmente, está relacionada com mudanças mais amplas do 
capitalismo mundial, com a superação do modelo fordista de acumulação e a transição e afirmação de um regime de acumulação flexível, próprio da economia mundializada-financeirizada do século XXI.

Posteriormente, abordaremos as principais características econômicas e sociais atuais de Porto Alegre e sua Região Metropolitana, relacionando a mesma com os traços mais gerais da metropolização brasileira, especialmente no que se refere à desigualdade socioespacial que, nas últimas décadas, configura-se com uma maior complexidade ao se moverem pelo espaço metropolitano as classes e grupos sociais. $\mathrm{O}$ tradicional modelo "centro-periferia" da metrópole está definitivamente superado com as novas configurações territoriais das classes e grupos sociais e com a emergência das novas centralidades e das novas periferias. Abordaremos esta temática ao longo do artigo.

Finalizando, analisamos os desafios para a gestão do espaço metropolitano a partir das contradições políticas e sociais impostas pelo novo regime de acumulação urbano da metrópole e do novo modelo de metrópole emergente e à luz do Estatuto da Metrópole (Lei Federal 13.089 de 12 de janeiro de 2015) recentemente promulgado, o qual tenta, em parte, dar resposta aos problemas metropolitanos brasileiros.

\section{A metropolização contemporânea no mundo e na América Latina}

Já se configura quase como um consenso entre os pesquisadores que, no século XXI, a urbanização planetária entrou em uma nova fase, na qual os paradigmas e teorias construídos para a interpretação da fase anterior não conseguem dar conta da complexidade das questões e dos arranjos socioespaciais que a caracterizam. É bastante conhecida a profusão de neologismos que visam dar conta da nova forma urbana e metropolita- 
na que se espalha por todos os continentes habitados de nosso planeta. A nova urbanização mundial se manifesta nas "megarregiões urbanas", nos "corredores urbanos", nas "pós-metrópoles", nas "cidades-regiões globais", entre outros conceitos formulados ou reformulados para explicar o mundo urbano em intensa transformação ${ }^{1}$. Contudo, não se pretende, aqui, ficar na discussão de conceitos para explicar as formas espaciais resultantes, e sim, interessa-nos discutir os processos socioespaciais e suas consequências nos territórios locais.

A metropolização contemporânea tem origem nos processos de concentração urbano-industrial ocorridos na segunda metade do século $X X$, quando a industrialização fordista concentrou indústrias de bens de consumo duráveis no entorno das grandes cidades, originando as áreas metropolitanas fundadas no modelo centro-periferia que opunha as metrópoles industriais e as cidades dormitórios. Nessa etapa os processos de dispersão estavam diretamente ligados às dinâmicas da cidade central.

Em etapas posteriores, nos territórios metropolitanos consolidados, verificam-se novas dinâmicas que conduzem a um novo modelo de cidades que pouco tem a ver com as formas e escalas do modelo "tradicional" (Montejano Escamilla, 2013:38). Se, em uma primeira etapa da metropolização (a "suburbanização"), as atividades e as dinâmicas estavam intimamente ligadas com o que ocorria no centro, em um momento posterior (o da "dispersão urbana"), relacionado com a reestruturação do fordismo, os laços de dependência com a cidade central se transformam e emergem novas centralidades.

\footnotetext{
${ }^{1}$ Para uma discussão dos "neologismos" utilizados para explicar as cidades e a urbanização mundial ver Vicente Rufí (2003) e Soares (2008). A série "State of the World's Cities", publicada pela agência Habitat das Nações Unidas oferece um panorama detalhado e compreensivo da urbanização mundial no século XXI a partir de dados estatísticos e pesquisas temáticas (disponível em http://unhabitat.org/series/state-of-the-worlds-cities-reports/)
} 
Segundo diferentes analistas, estamos diante de mudanças radicais da forma urbana e metropolitana, a qual afeta também nossos paradigmas de análise. Por exemplo, o sociólogo Manuel Castells considera que

El proceso global de urbanización que estamos experimentando en los inicios del siglo XXI se caracteriza por la formación de una nueva arquitectura espacial en nuestro planeta, constituida por redes globales que conectan tanto las regiones metropolitanas más importantes como sus zonas de influencia. Dado que la forma de interconexión de las distribuciones territoriales también se extiende hacia la estructura intrametropolitana, nuestra comprensión de la urbanización contemporánea debe comenzar con el estudio de tales dinámicas de interconexión tanto en los territorios abarcados por dichas redes como en las localidades excluidas de la lógica dominante de integración espacial global (Castells, 2013, s.p.).

Para o urbanista italiano Francesco Indovina, a "metropolização atual do território" seria "a tendência à integração de vários conjuntos urbanos e inclusive dos territórios de urbanização difusa". Trata-se de "uma integração completa que inclui as atividades econômicas, as relações sociais, a vida cotidiana, a cultura". Ou seja, um processo pelo qual os intercâmbios ocorrem sob estruturas e escalas completamente distintas e em contextos completamente novos (Indovina, 2007: 22, citado por Montejano Escamilla, 2013).

Já Edward Soja (2008), geógrafo estadunidense, considera que a pós-metrópole, ou a metrópole pós-moderna, pós-fordista e pós-keynesiana representa algo considerablemente nuevo y diferente. Se trata del resultado de una era de intensa y extensa reestructuración, con un impacto más profundo, sobre cada una de las facetas de nuestras vidas, que en ningún otro periodo que haya tenido lugar durante los últimos dos siglos —es decir, desde los orígenes de la ciudad capitalista industrial. Y como tal, esta metrópolis requiere ser estudiada en sí misma y no sólo como una extensión geohistórica, especialmente en aquellas regiones del mundo donde la transición postmetropolitana ha avanzado con mayor profundidad (2008:218). 
Estamos diante de uma "metamorfose metropolitana", na qual, as transformações são profundas e resultam em "uma mudança completa na estrutura, função e forma da metrópole" (Lencioni, 2011:51). Esta metamorfose socioespacial tem como característica a formação de uma ampla "região urbana" de limites imprecisos, dinâmicos e difusos; a redefinição das hierarquias entre as cidades da região; a polinucleação e a ampliação da intensidade e da direção dos fluxos internos, tanto entre centro e periferias, como entre os diferentes núcleos e espaços periféricos (Lencioni, 2011:52).

No caso da América Latina, as transformações socioespaciais nas metrópoles também são significativas e intensas. Diversos autores se debruçam sobre o tema, partindo de dois pontos de análise: (I) das mudanças em cursos nas metrópoles e grandes cidades latino-americanas; (II) de quais mudanças são influenciadas pela nova etapa político-econômica do capitalismo mundial (a sua mundialização financeira) e quais representam a continuidade das particularidades do processo de urbanização latino-americano. Podemos citar diversos autores latino-americanos que analisam a metropolização do continente do ponto de vista endógeno, isto é, tentando estabelecer uma teoria da urbanização latino-americana a partir de referenciais construídos na história e na economia do continente ${ }^{2}$. Entre esses autores, temos os trabalhos de Carlos de Mattos (2006, 2007, 2014), nos quais o urbanista discute as tendências constitutivas da metropolização e da urbanização latino-americanas.

Para Carlos de Mattos, as metrópoles latino-americanas estão passando por uma autêntica "metamorfose urbana" advinda da radicalização do processo de financeirização e mercantilização da produção da cidade, o

\footnotetext{
${ }^{2}$ Uma excelente coletânea pode ser encontrada em Ramírez e Pradilla Cobos (2013).
} 
qual produz um intenso ciclo de reestruturação econômica, social e, por conseguinte, urbana e metropolitana. Entre as principais características deste novo ciclo temos "cinco tendências constitutivas" da metropolização latino-americana, a saber: as novas estruturas produtivas e a nova dinâmica urbana; a desregulação dos mercados de trabalho e a constituição da cidade desigual; os novos negócios imobiliários e a nova regulação urbanística; a explosão da mobilidade e uma nova morfologia urbana (novas centralidades, novas periferias, urbanização dispersa) e os novos artefatos urbanos e a padronização da paisagem urbana das cidades (Mattos, 2006).

Estaríamos assim diante de um "novo modelo da metrópole latino-americana" (Janoschka, 2002), o qual exacerba tendências de períodos anteriores da metropolização apresentando-se mais complexo, disperso e fragmentado, como apontam diferentes autores ${ }^{3}$. Este novo modelo "globalizado" estaria se generalizando por todo o continente, do Rio Grande ao Cone Sul, guardando suas especificidades regionais e locais, mas também podendo ser, de alguma forma, identificado na própria metropolização brasileira.

Esse contexto é apontado por análises recentes sobre a financeirização da urbanização brasileira, relacionada tanto com o recente ciclo de expansão da economia, especialmente no boom da construção civil baseado na expansão dos fundos imobiliários, do crédito privado e nos fundos públicos (Programa Minha Casa Minha Vida), como também dos megaeventos esportivos (Copa do Mundo de 2014 e Jogos Olímpicos de 2016), os quais aceleraram um novo modelo de governança e um novo

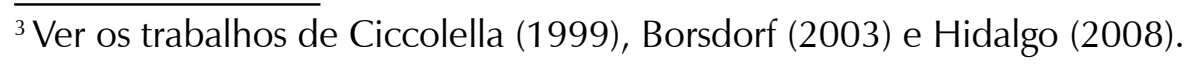


ciclo de acumulação urbana nas principais metrópoles brasileiras (Ribeiro e Santos Jr., 2013 e Rolkik, 2015). Será a partir desse cenário que realizaremos nossa análise da metropolização brasileira.

\section{A metropolização brasileira no século XXI}

No caso brasileiro, após a longa década da reestruturação neoliberal (anos 1990), a partir de 2004, houve a tentativa de implantação de um novo modelo de desenvolvimento, no qual o Estado novamente se apresentou como um dos indutores e protagonistas do crescimento econômico, o modelo chamado de "neodesenvolvimentista". Essa denominação não é consensual entre os analistas, especialmente entre os críticos das políticas econômicas, as quais são consideradas por muitos como uma continuidade do "período neoliberal" (1990-2004), contemplando uma pequena derivação nas políticas sociais ("social-neoliberalismo") ou no financiamento público aos grandes grupos econômicos ("neoliberalismo de Estado"). As críticas ao modelo foram reforçadas a partir das políticas de ajuste fiscal adotadas para combater a recessão econômica iniciada em 2014, promovendo cortes nos gastos sociais e a ampliação das desigualdades econômicas, o que teria colocado em xeque as conquistas sociais do período 2004-20124.

O que podemos afirmar é que o novo ciclo de desenvolvimento econômico, que perdurou entre 2005 e 2014, caracterizou-se por uma ampla reestruturação socioespacial, especialmente reestruturação urbana, que

\footnotetext{
${ }^{4}$ Muitos acadêmicos preferem não definir o modelo econômico colocando as três opções como "projetos em disputa" pelas forças políticas, econômicas e sociais. Sobre as diferentes posições neste debate ver Boito Jr. (2012) e Sampaio Jr. (2012).
} 
atingiu todo o território nacional, mas com forte repercussão nos principais espaços urbanos e metropolitanos. Essa reestruturação está baseada no crescimento das atividades econômicas agrárias (o agronegócio), industriais, comerciais e de serviços. De fato, o país saiu de longo período de letargia econômica, no qual se mantinha como décima economia mundial, para uma nova era de crescimento, no qual alcançou a sexta posição entre as grandes economias mundiais, na esteira do crescimento dos chamados "países emergentes", capitaneados pelo crescimento acelerado da economia chinesa. Nesse período, ocorreu um forte crescimento da exportação de commodities, a expansão da produção energética, um novo ciclo da indústria naval, bem como o crescimento da indústria de bens de consumo duráveis (eletrodomésticos e automobilística). Concomitantemente, ocorreu diminuição dos índices de desemprego e o crescimento da renda da população, seja pelos rendimentos do trabalho, seja pelos efeitos das políticas sociais redistributivas, o que provocou explosão do consumo das famílias e uma forte expansão do setor de serviços no país.

O crescimento brasileiro teve um forte componente de financiamento público, seja pelo fomento do Banco Nacional de Desenvolvimento Econômico e Social (BNDES), especialmente para os grandes grupos agroexportadores nacionais, seja pelas obras públicas de infraestrutura do Programa de Aceleração do Crescimento (PAC) em suas diferentes fases, os quais também contribuíram para a expansão do emprego e da renda da população. Considera-se, ainda, o novo ciclo de desenvolvimento da construção civil e da produção imobiliária, o qual se produziu em duas frentes principais: por um lado, a expansão dos empreendimentos imobiliários de alto padrão e para a classe média, ocupando setores valorizados do espaço urbano, elevando nacionalmente o preço dos imóveis novos e usados. De outro, os projetos de habitação popular financiados pelo Programa Minha Casa Minha Vida (PMCMV), os quais ocuparam as peri- 
ferias urbanas, criando novos vetores de valorização. Ambas as expansões abriram novas fronteiras para o capital imobiliário e se produziram sobre espaços, muitas vezes, já ocupados por assentamentos informais consolidados, os quais sofreram processos de desintegração e expulsão/remoção para periferias ainda mais distantes.

O processo de urbanização brasileiro, iniciado nas primeiras décadas do século XX e intensificado a partir da segunda metade do mesmo, seguiu tendências mais gerais da urbanização latino-americana, mas com características próprias, oriundas do processo histórico de ocupação do território. Essa ocupação, até os anos 1930, caracterizava-se como um "arquipélago de economias regionais", conforme análises clássicas5. Essa "economia de arquipélago" ${ }^{\prime \prime}$ gerou redes urbanas independentes, com poucos pontos de contato até os anos 1950. Elas eram polarizadas por diferentes centros regionais, que após a unificação do mercado nacional e a industrialização, nos anos 1970, transformaram-se nas nossas primeiras metrópoles.

As primeiras regiões metropolitanas institucionalizadas no Brasil, no início da década de 1970 (1973-1974)7 , em plena ditadura militar, são produtos desse processo. Eram caracterizadas, em sua maioria, por uma industrialização fordista, albergando algumas indústrias de base (refinarias de petróleo e siderúrgicas, por exemplo) e estruturadas no modelo centro-periferia, com o núcleo central da metrópole ocupado em sua maioria pelas elites e classes médias e a periferia metropolitana como lócus de reprodução da força de trabalho operária e trabalhadora nos serviços menos qualificados.

\footnotetext{
${ }^{5}$ Referimo-nos ao trabalho de Celso Furtado (2000 - a primeira edição é de 1959, pela Editora Nacional) seguido dos trabalhos de Francisco de Oliveira (1977) e Wilson Cano (2007, original de 1981).

${ }^{6}$ Não confundir com o conceito do economista francês Pierre Veltz em Mondialisation, villes et territoires. L'économie d'archipel (1996).

${ }^{7}$ São as nove regiões metropolitanas "originais": São Paulo, Belo Horizonte, Porto Alegre, Curitiba, Salvador, Recife, Fortaleza, Belém e, posteriormente, o Rio de Janeiro.
} 
Nessas primeiras décadas do século XXI, o Brasil se apresenta como um país fortemente urbano e metropolitano, com uma população de mais de 205 milhões de habitantes e com mais de 85,1\% da população vivendo em áreas consideradas urbanas. Em 2004, a população urbana era de 82,7\% (IBGE, 2015:11), o que demonstra que a concentração da população no território segue sua trajetória aproximando-se do limite.

Ainda que a definição oficial brasileira de "área urbana" seja baseada em critérios político-administrativos, é indiscutível que o "urbano" como processo socioespacial e modo de vida é dominante no território brasileiro, restando áreas residuais, enclaves territoriais das populações tradicionais, que lutam para manter seu território e preservar sua identidade étnica e cultural. Entretanto, mesmo nessas áreas, o poder de irradiação da sociedade urbana é forte, principalmente porque a integração social e cultural se produziu baseada nos meios de comunicação de massa nos anos 1970, especialmente a televisão: "cada vez mais as cidades, ou o espaço político e sociocultural formado a partir delas se tornaram o centro da organização da sociedade e da economia" (Monte-Mór, 2006:06).

A rede urbana brasileira, hoje, é complexa e hierarquizada, com distintos níveis e diferentes centros e graus de polarização dos fluxos no território (figura 1). O centro dominante dessa rede é formado pelas duas grandes metrópoles nacionais, com pretensões de "cidades globais": São Paulo e Rio de Janeiro. São Paulo, como centro financeiro e principal centro dinâmico do capitalismo brasileiro; Rio de Janeiro, como capital cultural, imagem do Brasil para o mundo e centro da economia do petróleo ${ }^{8}$.

\footnotetext{
${ }^{8}$ Diversos estudos inserem estas metrópoles no "privilegiado clube das cidades mundiais" e alguns consideram que ambas formam a "região urbana global" brasileira que engloba as duas metrópoles e suas respectivas regiões metropolitanas e estendendo-se de Campinas, da Baixada Santista e do Vale do Paraíba à Região dos Lagos (RJ). Ver o trabalho de R. C. de Albuquerque, inserido no estudo Rio-São Paulo: Cidades Mundiais - desafios e oportunidades (Rezende; Lima, 1999).
} 
São Paulo é o centro econômico-financeiro do país, uma cidade mundial cuja influência extrapola o território nacional, com ramificações em parte da rede urbana sul-americana. O município de São Paulo concentra $10,7 \%$ da economia brasileira e a Região Metropolitana com 17\%. Somente a Região Metropolitana de São Paulo participa com 10,3\% da população nacional, percentual semelhante a do Estado de Minas Gerais, o segundo estado mais populoso do país (IBGE, 2015).

O Rio de Janeiro, segunda metrópole do país, após um longo período de crise econômica, social e urbana, renasceu para a economia internacional por seus vínculos com a economia do petróleo, pelo turismo internacional e pelos megaeventos (esportivos, culturais). A imagem de "cidade empresa", por meio do planejamento estratégico, jogou um papel nesse cenário. Em um segundo nível, encomtram-se Brasília, a capital federal, e as metrópoles que polarizam as redes urbanas regionais. São metrópoles com mais de um milhão de habitantes que conformam regiões metropolitanas no seu entorno. Algumas regiões metropolitanas concentram uma população superior a três milhões de habitantes ${ }^{9}$.

\footnotetext{
${ }^{9}$ De acordo com o Instituto Brasileiro de Geografia e Estatística (IBGE), as metrópoles nacionais brasileiras são: São Paulo, Rio de Janeiro, Brasília, Belo Horizonte, Porto Alegre, Curitiba, Recife, Salvador, Fortaleza, Belém do Pará, Manaus e Goiânia. Além destas podemos adicionar à relação dos "espaços metropolitanos" brasileiros as regiões metropolitanas de Campinas, Vitória e Florianópolis (IBGE, 2008).
} 


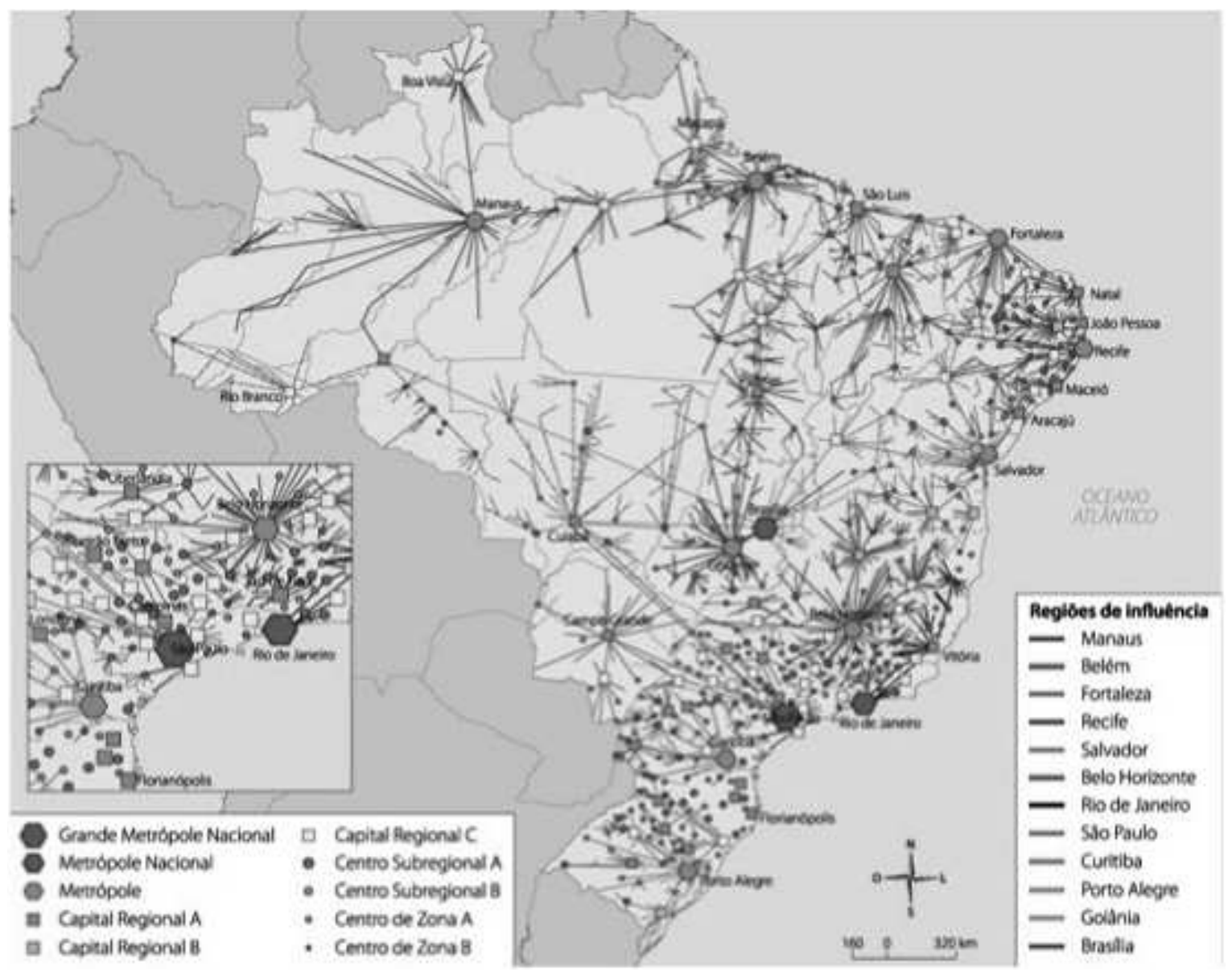

Figura 1. As metrópoles e a rede urbana brasileira

Fonte: IBGE (2008).

Conjuntamente a essas metrópoles, nas regiões mais desenvolvidas do território nacional, temos uma diversidade de formas de concentração urbana (conurbações, aglomerações urbanas, corredores urbanos, cidades médias), que constituem a rede urbana nacional. Esta diversidade de formas de concentração urbana se manifesta principalmente no centro-sul (a "região concentrada"10), que reúne a indústria mais dinâmica e a

${ }^{10}$ Expressão utilizada por Milton Santos para designar a região de maior concentração demográfica e econômica (indústria, comércio, serviços, agropecuária moderna) do país. Compreende as regiões Sudeste, Sul e parte do Centro-oeste (especialmente o Mato Grosso do Sul e Goiás). 
agropecuária mais modernizada e voltada para o mercado exportador (o chamado "agronegócio). É nesta região que o "conteúdo tecnológico do território" (o "meio técnico-científico-informacional") é mais desenvolvido, os fluxos são mais densos, intensos e integrados e a concentração urbana e econômica revela toda sua magnitude, diversidade e complexidade de processos (Santos, 1993; Santos e Silveira, 2001).

Em geral, a metropolização se caracteriza pela concentração seletiva de capitais, estruturas de gestão, bens, serviços, pessoas e informações em alguns espaços privilegiados pela sua posição no território. No caso brasileiro, todas as grandes regiões do país apresentam suas metrópoles, espaços polarizadores da rede urbana regional, ou seja, a metropolização já é um fenômeno presente em todo o território brasileiro.

Entretanto, as metrópoles brasileiras são bastante desiguais em sua importância para o funcionamento político e econômico do país. É a partir de três grandes centros (São Paulo, Rio de Janeiro e Brasília) que se realiza a gestão econômica do território nacional, embora ocorra uma certa desconcentração econômica rumo às metrópoles regionais e, mesmo, cidades médias (especialmente na região concentrada). Essas, além de atraírem empresas, também estão recebendo novos serviços e quadros profissionais qualificados, sejam ligados à indústria, aos serviços ou à agricultura moderna.

O último ciclo de crescimento econômico do país caracterizou-se pelo forte investimento do Estado e do capital privado em capital fixo (autoestradas, portos, aeroportos, sistemas de mobilidade urbana). MeIhoraram as condições gerais de produção ao se propiciar maior fluidez ao território, uma vez que um componente importante do crescimento econômico foram as exportações de commodities e alguns produtos industrializados. Na escala regional, esta homogeneização das condições gerais de produção contribuiu para a difusão concentrada das atividades 
econômicas pelo território. Em muitos lugares nos quais estas atividades se territorializam, temos também a concentração da urbanização que muitas vezes são consideradas "metropolização". Entretanto, a denominação "região metropolitana" tem sido banalizada no Brasil, o qual já conta com mais de 80 espaços institucionalizados como sendo metropolitanos ${ }^{11}$. A presença no ordenamento territorial brasileiro desses espaços indica que novos processos estão ocorrendo na urbanização e metropolização brasileiras. Não obstante, como será visto adiante, a definição "formal" de "regiões metropolitanas" causa graves distorções.

O ciclo recente de crescimento econômico realizou uma significativa redistribuição de renda, sem romper, porém, com as desigualdades históricas da nossa sociedade. Tanto em termos sociais, como em termos regionais. Ou seja, persistem as diferenças entre os espaços "luminosos" e os espaços "opacos" do território (Santos e Silveira, 2001). Os primeiros, com a presença de capitais e com forte integração entre si e em conexão com a economia global; e os segundos, ainda muito dependentes das atividades locais, de uma agropecuária pouco modernizada e de indústrias pouco dinâmicas. Assim, a metropolização brasileira reproduz as dualidades da estrutura socioterritorial do país: primeiro ao ampliar as desigualdades entre espaços metropolitanos e não-metropolitanos, uma vez que o novo ciclo econômico favorece os espaços concentrados, pois são eles os mais capazes de atrair o grande capital; segundo, ao ampliar as desigualdades intrametropolitanas.

Em seu posicionamento no espaço metropolitano, os capitais buscam posições privilegiadas, espaços nobres ou de valorização nas metrópoles. Se os espaços não são valorizados, tal valorização se produz com a

\footnotetext{
${ }^{11}$ O Estatuto da Metrópole, lei federal no 13.089 de 12 de janeiro de 2015 representa a tentativa da esfera federal de regular a institucionalização de regiões metropolitanas por parte dos estados da federação sem critérios mínimos nacionais.
} 
captura das rendas diferenciais do solo urbano, especialmente as derivadas dos investimentos públicos em infraestruturas como as de mobilidade urbana. As rendas diferenciais urbanas também são capturadas pelos grupos sociais dominantes, especialmente os setores rentistas ligados ao capital financeiro e imobiliário, os quais localizam seus espaços de habitação nos setores privilegiados da metrópole. O mercado imobiliário em crescimento concentra seus investimentos nesses setores, nos espaços tradicionais de localização das classes médias e altas, ou produzindo novos espaços de valorização, por expansão dos setores já privilegiados ou na criação das chamadas "novas periferias". Essas se caracterizam por espaços de experimentação, de "novas formas de habitar" na metrópole (condomínios fechados, comunidades exclusivas, enclaves fortificados). Há o predomínio da ocupação de baixa densidade (urbanização dispersa) e elevada qualidade ambiental do ambiente construído, especialmente em áreas de amenidades naturais ${ }^{12}$. As novas periferias carregam as estruturas de mobilidade urbana, mormente as de mobilidade urbano-regional, pois se localizam ao longo de eixos viários importantes e seus habitantes deslocam-se exclusivamente pelo transporte individual.

Por outro lado, as "velhas" periferias metropolitanas acumulam problemas urbanos e populações excluídas dos êxitos do modelo econômico. Perduram as moradias precárias, com ausência de serviços básicos, problemas socioambientais (falta de saneamento, acúmulo de resíduos sólidos, áreas de risco ambiental) e violência. Estabelece-se, assim, uma dualidade entre "novas" e "velhas" periferias. Contudo, como parte da velha periferia está sendo "empurrada" para localizações mais distantes do centro metropolitano, ou ocupando áreas de alto risco ambiental, ela

\footnotetext{
$\overline{12}$ É importante salientar que esta ocupação se dá, muitas vezes, ocasionando graves danos ambientais, pois os novos espaços residenciais se apropriam das amenidades naturais que são fortemente impactadas e artificializadas por seus novos usos.
} 
tende a se caracterizar como uma "hiperperiferia" (Torres et al, 2003), uma periferia com maior acúmulo de problemas e riscos sociais e ambientais. Não raramente representam processos de segregação socioespacial.

\section{A Região Metropolitana de Porto Alegre: constituição e evolução}

Até aqui, apresentamos, de modo abrangente e sintético, as características gerais da metropolização mundial, latino-americana e brasileira. A partir de agora, passamos a abordar como essas tendências rebatem no espaço metropolitano de Porto Alegre. O esquema abaixo representa o modelo de análise da reestruturação metropolitana (Figura 2). 


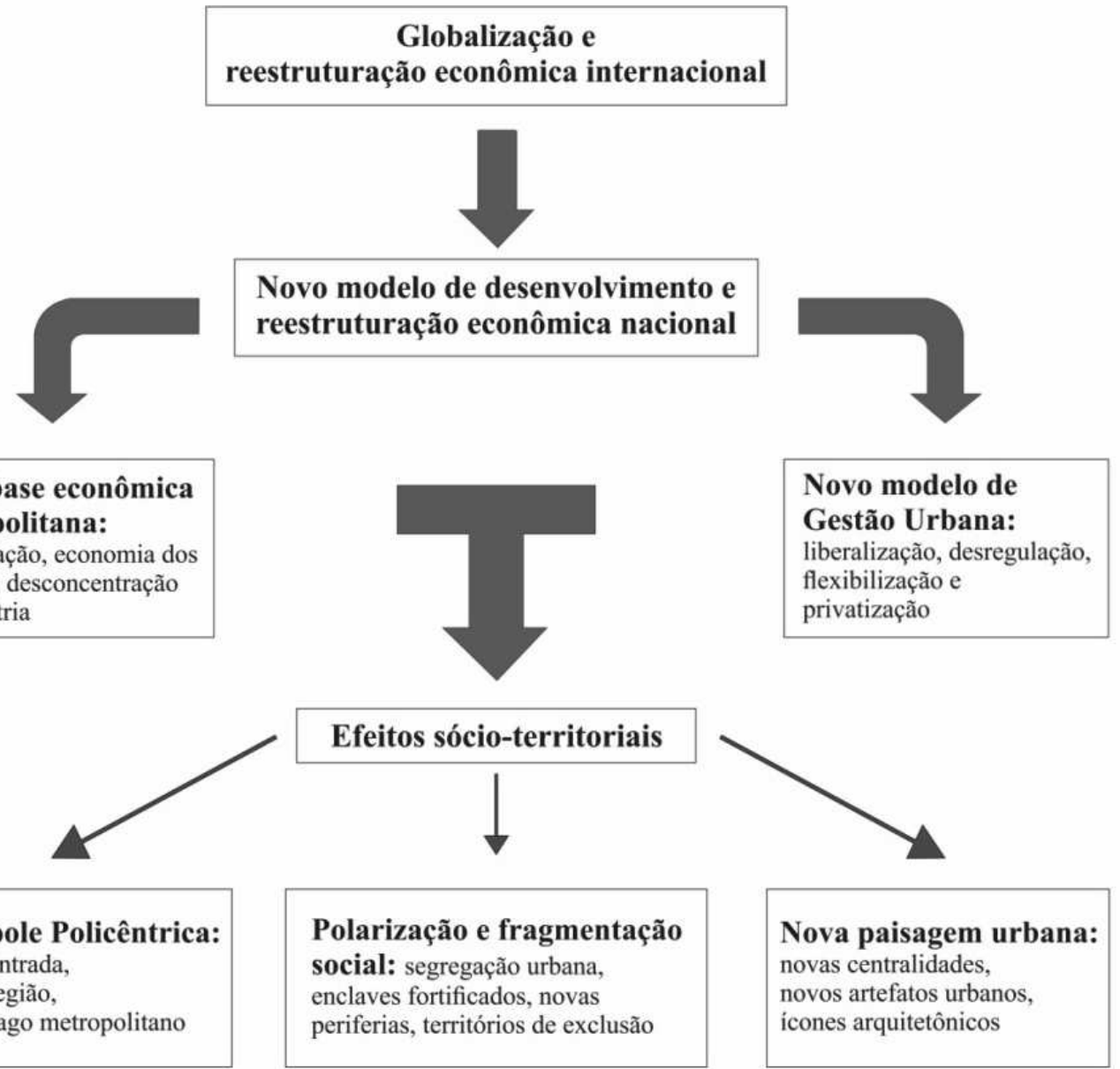

Figura 2. Esquema analítico da reestruturação metropolitana

Fonte: Soares, 2015 (baseado em Mattos, 1999).

Nossa análise parte das mudanças mais amplas advindas do processo de globalização econômica e da reestruturação da economia capitalista do final do século XX e de como essas transformações influenciaram a mudança do padrão de acumulação e de desenvolvimento socioeconômico do capitalismo brasileiro. Dessas mudanças mais gerais, derivam dois processos significativos para a reestruturação metropolitana: a estruturação de uma nova base econômica metropolitana (apoiada na des- 
concentração da indústria e na economia de serviços) e a emergência de um novo modelo de gestão urbana, no qual prevalece a liberalização, a desregulação e a flexibilização da produção da cidade.

Essa nova configuração resulta em três efeitos sócio-territoriais importantes: a emergência da metrópole policêntrica (desconcentrada, de múltiplos centros), a polarização e fragmentação sociais (com o reforço das desigualdades e da segregação urbana) e uma nova paisagem urbana, onde se destacam "novos artefatos urbanos" e novos ícones arquitetôni$\cos ^{13}$. Evidentemente essa nova configuração metropolitana não se impõe como um todo sobre a metrópole, ou seja, nela persistem espaços produzidos com as características do modelo anterior. Todavia, apresenta-se como tendência já dominante, especialmente nos espaços mais valorizados e dinâmicos da metrópole e da sua RM.

É preciso salientar que a Região Metropolitana de Porto Alegre (doravante RMPA) constituiu-se ainda sob a égide do modelo fordista de desenvolvimento. Ao final dos anos 1960, o território, que em 1973 viria a ser institucionalizado como RMPA, já apresentava sinais de conurbação ao longo do eixo da BR-116. Nesse período e na década de 1970, a RMPA recebeu grandes estruturas que consolidaram a morfologia metropolitana: a Refinaria de Petróleo Alberto Pasqualini (Canoas), a Companhia Siderúrgica Riograndense (Sapucaia do Sul) e o Polo (sic) Petroquímico (Triunfo). Essas grandes estruturas industriais fordistas, aliadas a um parque industrial metalomecânico, coureiro-calçadista, químico e alimentar configuraram a estrutura industrial da RMPA. Ao mesmo tempo, o modelo espacial metropolitano replicava o modelo centro-periferia vigente em outras áreas metropolitanas. Esse modelo considerava os espaços da metrópole (Porto Alegre,

\footnotetext{
${ }^{13}$ Referimo-nos a edifícios emblemáticos que se destacam na paisagem urbana, a exemplo de shopping centers, centros empresariais, torres comerciais e, até mesmo, equipamentos culturais como teatros e museus.
} 
centro de gestão e de serviços, lócus das classes dirigentes e de maior poder aquisitivo) e os da região metropolitana (cidades industriais e cidades dormitório, espaços produtivos e de reprodução da força de trabalho).

Uma característica importante que acompanha a Região Metropolitana de Porto Alegre desde sua estruturação inicial é a presença de duas "áreas de concentração de população" ou "redes urbanas" distintas - mas complementares - em seu território (representadas na Figura 3): a porção da RMPA polarizada diretamente por Porto Alegre (RMPA-POA) e o conjunto de cidades polarizadas por Novo Hamburgo e São Leopoldo (Vale do Sinos ou RMPA-Vale) ${ }^{14}$. Indiscutivelmente, Novo Hamburgo constitui-se como um polo econômico e urbano importante ao norte da RMPA, rivalizando, em alguns aspectos, com a metrópole Porto Alegre. Por outro lado, no período atual, outras centralidades importantes constituem-se na Região Metropolitana, especialmente Canoas e Gravataí.

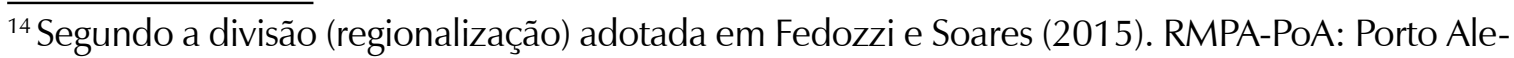
gre, Alvorada, Canoas, Cachoeirinha, Eldorado do Sul, Esteio, Glorinha, Gravataí, Guaíba, Nova Santa Rita, Sapucaia do Sul, Triunfo e Viamão. RMPA-Vale: Novo Hamburgo, São Leopoldo, Araricá, Campo Bom, Dois Irmãos, Estância Velha, Ivoti, Nova Hartz, Parobé, Portão e Sapiranga.
} 


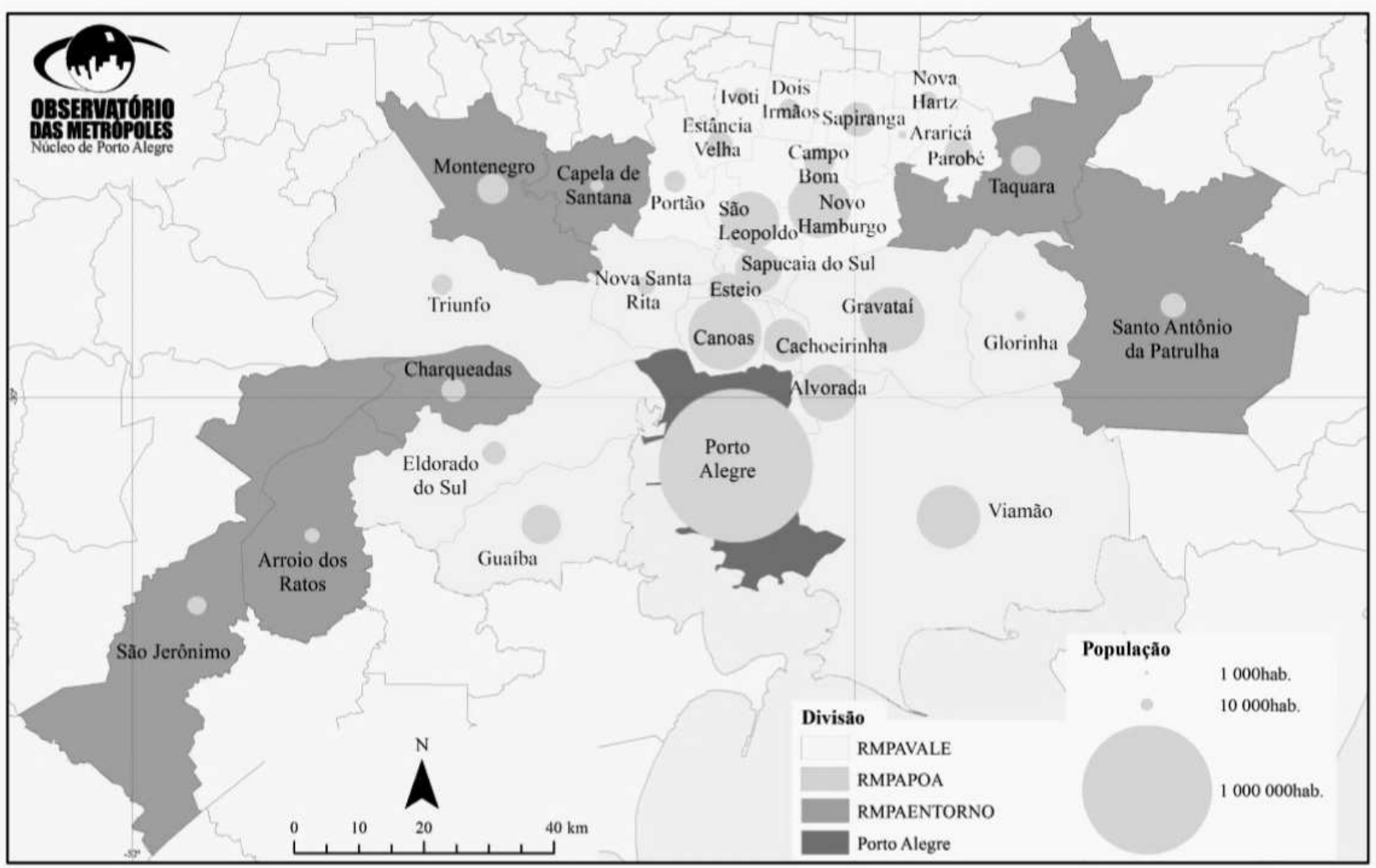

Figura 3. Regionalização da RMPA

Fonte: Fedozzi e Soares, 2015, p. 37.

A partir dos anos 1990, período da reestruturação neoliberal, uma série de mudanças importantes se manifestou na RMPA. A aceleração do processo de desindustrialização do município de Porto Alegre redundou na dispersão da indústria pelos principais eixos de mobilidade da RMPA. As novas implantações industriais têm muito mais o caráter de "enclave" industrial do que de nova concentração de empresas ${ }^{15}$.

Hoje, temos uma região metropolitana muito mais complexa. A RMPA, hoje, apresenta uma morfologia dispersa, multicêntrica. A indús-

${ }^{15}$ Vide os exemplos da fábrica da General Motors em Gravataí, da AMBEV em Viamão e da Souza Cruz em Cachoeirinha (recentemente fechada). 
tria já não é mais o único motor econômico, a economia de serviços é fortemente dominante, tanto na composição do Produto Interno Bruto (PIB), como na composição da força de trabalho. Uma nova economia metropolitana está se constituindo, especialmente no núcleo da metrópole: os serviços avançados têm uma grande importância na economia de Porto Alegre, além da nova economia industrial advinda das empresas de alta tecnologia. Como resultado desses diferentes processos, temos uma grande diversidade social na RMPA, além de maior segregação socioespacial. É o que mostra o perfil socioespacial da RMPA.

\section{A Região Metropolitana de Porto Alegre: mudanças no perfil socioespacial (1980-2010) ${ }^{16}$}

Desde sua institucionalização como Região Metropolitana, e de acordo com as reestruturações e mudanças do modelo de desenvolvimento nacional, o perfil socioespacial da RMPA foi se transformando, conforme demonstra a análise da sua estrutura econômica e sociopopulacional. Na análise da relação entre a estrutura socioprofissional e as características socioespaciais do território, encontramos a correspondência na formação de determinados espaços consolidados e habitados predominantemente por determinados grupos sociais. Esses são aqui chamados de "categorias socio-ocupacionais" que compreendem os grupos dirigentes, profissionais de nível superior, pequenos empregadores, ocupações médias, trabalhadores do terciário especializado, trabalhadores do secundário, trabalhadores do terciário não-especializado e os agricultores. Já para os espaços homogêneos de moradia dessas categorias, temos as "tipologias socioespaciais" classificadas como de tipo superior, médio, operário,

\footnotetext{
${ }^{16}$ Análise baseada na pesquisa Estrutura social e organização social do território: Região Metropolitana de Porto Alegre - 1980-2010 apresentada em Marmarella et al. (2015).
} 
popular e agrícola. É do cruzamento dessas duas classificações que delimitamos o perfil socioespacial da RMPA.

Partindo de 1980, a análise do perfil social metropolitano identificava a presença de uma estrutura socio-ocupacional dual, na qual as categorias médias (trabalhadores do terciário superior), somadas às do proletariado (industrial e do setor terciário), correspondiam a mais de $78 \%$ da população ocupada. Somente o proletariado secundário equivalia a 31\% dos ocupados metropolitanos. Já as "pontas" da hierarquia - o conjunto das elites, dirigentes, intelectuais, a pequena burguesia e o "subproletariado" (trabalhadores não-especializados), associado aos agricultores, eram equivalentes numericamente (11\%).

Na década de 1980, a análise dos perfis sociais a partir da divisão intrametropolitana revelava importantes diferenças: Porto Alegre caracterizava-se pela predominância das classes médias (35\%), seguida do proletariado terciário (21\%). Porto Alegre era, naquele momento, a moradia de $18 \%$ dos trabalhadores do setor secundário (a maioria operários da construção civil). Na RMPA-PoA, predominava o proletariado secundário $(41 \%)$, porém mais vinculado à indústria moderna (metalomecânica e química). A RMPA-Vale concentrava a moradia dos operários, com o proletariado secundário e terciário equivalendo a $66 \%$ dos ocupados. A indústria tradicional (coureiro-calçadista) ocupava 37\% dos operários fabris.

Entre 1980 e 1991, foi evidente o processo de elitização em Porto Alegre, com o crescimento das áreas de tipo superior. Fora da capital, apenas em São Leopoldo (RMPA-Vale) foi identificada uma área de tipo superior. Também foi evidente a existência do processo de segregação socioespacial: ao mesmo tempo em que as elites se concentraram em setores e bairros nobres da metrópole, ocorreu o aumento da periferização da moradia das camadas populares (Figura 4). 


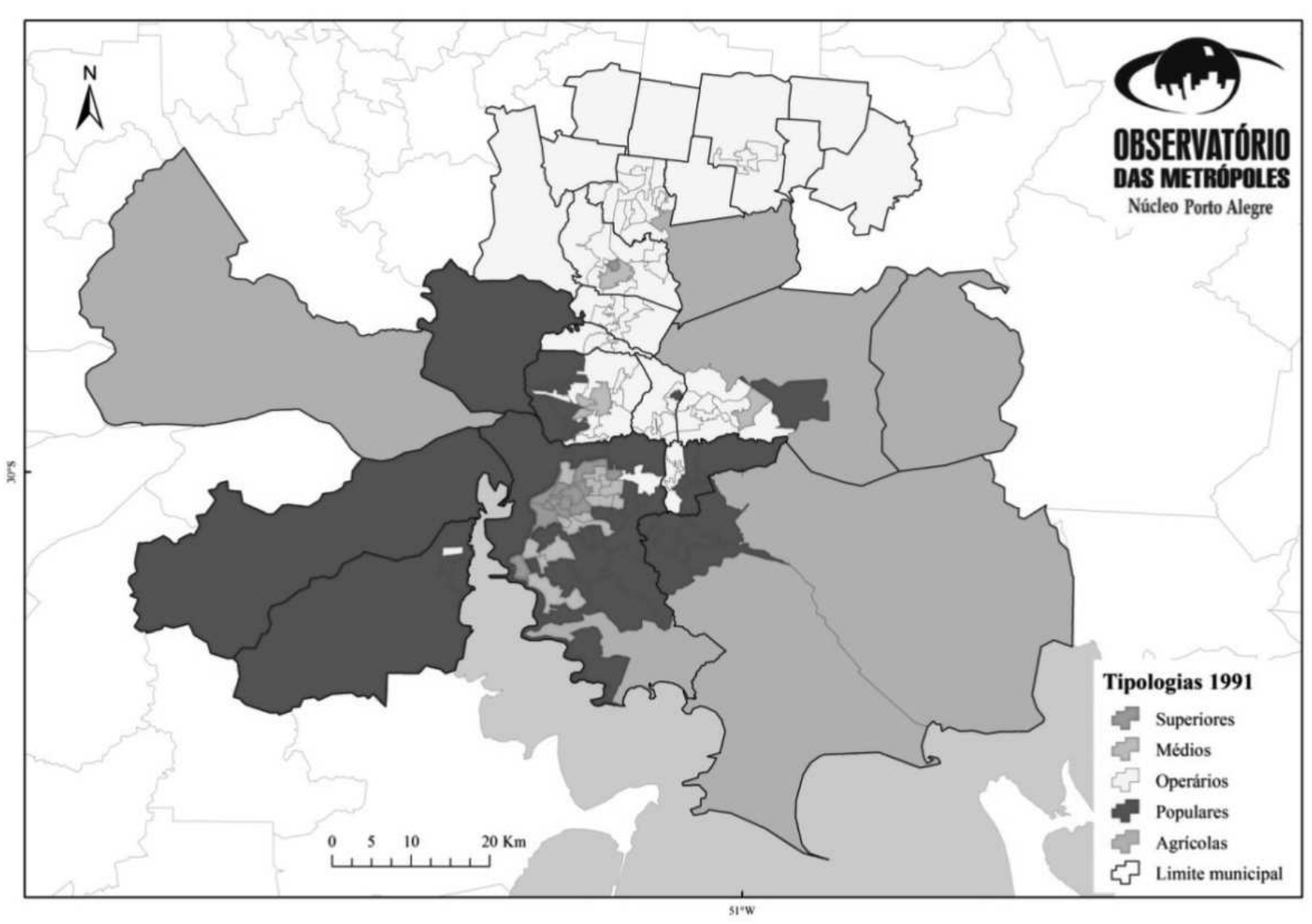

Figura 4. RMPA: tipologias socioespaciais (1991)

Fonte: Mammarella et all (2015), p. 168.

Na década de 2000-2010, o perfil socio-ocupacional da RMPA manteve-se em sua maior parte, operário e médio, porém com inversão da ordem de grandeza dessas duas categorias: em 2010 o percentual de operários era um pouco inferior ao das categorias médias (25\% e $29 \%$ respectivamente), o terciário especializado perfazia 17\%, aumentando o peso do terciário não-especializado (14\%) e dos profissionais de nível superior (11\%).

No Vale do Sinos (RMPA-Vale), o peso do operariado industrial continuou predominante (38\% dos ocupados), especialmente composto por operários da indústria tradicional e não-especializados. Esses últimos, que até o ano de 2000 representavam menos de 5\% dos ocupados, em 2010 
representavam 11\% dos trabalhadores residentes nesse recorte da RMPA. Ainda na RMPA-Vale, um quarto dos ocupados estava vinculado às ocupações médias, tendo crescido a importância e o peso das elites intelectuais e dos trabalhadores do terciário não-qualificado.

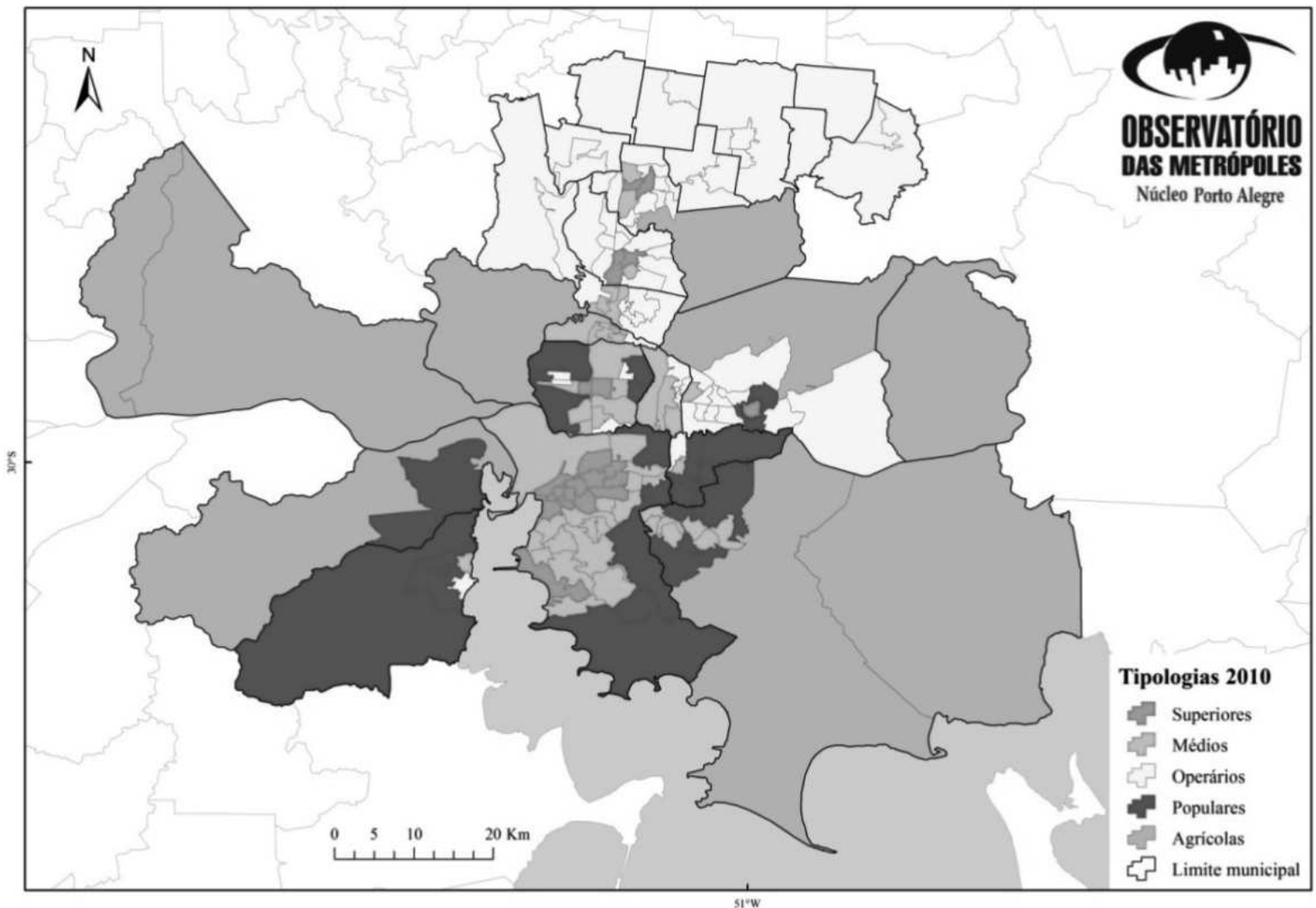

Figura 5. RMPA: tipologias socioespaciais (2010)

Fonte: Mammarella et all (2015), p. 173.

Sintetizando a caracterização geral da dinâmica do espaço intrametropolitano entre 1980 e 2010, observamos que, na RMPA, os grupos de áreas de tipo superior e os de tipo operário são mais homogêneos, caracterizados pela forte concentração da moradia dos dirigentes e dos profissionais de nível superior e dos operários, sendo que entre esses últi- 
mos distinguem-se os espaços de moradia dos trabalhadores da indústria moderna (RMPA-PoA) e dos trabalhadores da indústria tradicional (RMPA-Vale), como verificamos na Figura 5. Os espaços de tipo agrícola também tendem a uma relativa homogeneidade, mas se diferenciam dos anteriores por se referirem a áreas muito extensas, situadas na periferia da RMPA. Os espaços de tipo popular são bastante expressivos em termos sociais, com a moradia predominante dos trabalhadores da construção civil e do terciário não-especializado. Localizam-se nos extremos sul, leste e nordeste da capital, com uma clara situação de "extravasamento" para os municípios limítrofes que, nessas áreas, caracterizam-se como extensões da periferia da capital. Os espaços com menor grau de homogeneidade social são os de tipo médio, onde há maior mistura social, apesar de serem mais intensas as densidades das ocupações médias, dos pequenos empregadores urbanos e dos trabalhadores do terciário especializado.

No geral, as grandes alterações no perfil social do território metropolitano produziram-se nas duas últimas décadas do século XX. No primeiro decênio do século XXI, segundo a tipologia socioespacial de 2010, houve a consolidação, em alguns casos, e a ampliação, em outros, de determinados perfis sociais no espaço metropolitano. Uma visão geral do perfil socioespacial da Região Metropolitana de Porto Alegre revela uma nítida diferenciação entre suas subdivisões intrarregionais: em Porto Alegre e nas cidades do seu entorno (RMPA-PoA), vislumbra-se uma maior heterogeneidade social; no Vale do Sinos (RMPA-Vale) se mantém o padrão socioespacial relativamente homogêneo, com a predominância do tipo operário.

No núcleo da metrópole (Porto Alegre) não são encontrados os espaços de tipo operário e de tipo agrícola. A capital caracteriza-se por vastos territórios dos tipos médios, por uma forte concentração dos tipos superiores e pela presença do tipo popular na sua periferia, localização esta que se extravasa para o território dos municípios do seu entorno (es- 
pecialmente Alvorada e Viamão, mas também Canoas, Eldorado do Sul e Guaíba), formando uma extensa mancha de tipo popular ao sul da RMPA. Revela-se, assim, claramente, o processo de segregação dos espaços populares na periferia metropolitana.

Quanto aos espaços elitizados, de presença das categorias de tipo superior, evidenciam-se dois padrões: o primeiro, a presença de dois espaços homogêneos dos tipos superiores na capital: o amplo setor dos bairros de elite na porção norte-leste de Porto Alegre (Moinhos de Vento, Mont'Serrat, Auxiliadora, Petrópolis, Bela Vista, Boa Vista, Chácara das Pedras, Três Figueiras, entre outros) e o setor de elite nos bairros da Zona Sul (Vila Assunção, Ipanema, Jardim Isabel), os quais se situam agregados à área de amenidades do Rio Guaíba. O segundo, a partir de 2010, a presença de espaços elitizados (de tipo superior) em cidades de forte centralidade na Região Metropolitana (Novo Hamburgo e São Leopoldo, no Vale do Sinos, além de Canoas e Gravataí).

A localização de setores de elite nessas cidades, que também estão entre as mais populosas da RMPA, é evidenciada pela presença de novos equipamentos comerciais (shopping centers) e de serviços, bem como pelo estabelecimento de áreas residenciais nobres, especialmente em condomínios fechados.

\section{A Gestão Metropolitana e o Estatuto da Metrópole}

Face às transformações apontadas, conclui-se que a gestão da RMPA também se tornou mais complexa. A RMPA, ao longo de quatro décadas, cresceu em número de municípios (de 14 para 34), incorporando novos territórios ainda pouco conectados à dinâmica metropolitana e, ao mesmo tempo, contemplando uma economia mais complexa, espaços mais heterogêneos, bem como maior diversidade socioespacial, o que 
exige estruturas de gestão metropolitanas mais adequadas. Não obstante o reconhecimento de todas essas mudanças, até o momento, esse não se traduziu em uma nova gestão metropolitana compatível com essa realidade complexa e com a importância dessa região e os problemas socioeconômicos e ambientais que ela apresenta.

A Região Metropolitana de Porto Alegre já experimentou tentativas de gestão metropolitana, o que remete aos primórdios da sua institucionalização ${ }^{17}$. A constituição do "problema" metropolitano na RMPA antecedeu a normatização imposta pelo regime militar em 1973. Desde 1968, já havia sido instituído um grupo de trabalho para delimitar a "área metropolitana de Porto Alegre", composta então por 14 municípios, a partir de critérios relacionados ao fluxo do transporte, às funções urbanas e à continuidade dos espaços urbanizados. Em 1970, foi criado o Conselho Metropolitano dos Municípios (CMM) que visava à elaboração de estudos, planos e projetos para a região metropolitana, mediante convênios entre os municípios. O Grupo Executivo da Região Metropolitana de Porto Alegre (GERM) oferecia suporte técnico aos debates do CMM e elaborou o primeiro instrumento de planejamento, o Plano de Desenvolvimento Metropolitano. Este, embora não plenamente implementado, constituiu um importante episódio na história de construção de mecanismos de gestão metropolitana. Nesse contexto, em 1974, foi criada a Fundação Metropolitana de Planejamento Territorial (Metroplan), como órgão de apoio técnico ao Conselho Deliberativo, com a atribuição de realizar a programação e a execução de projetos e serviços de interesse comum da RMPA (Koch e Cortes, 2015: 319-320).

\footnotetext{
${ }_{17}$ Sobre a institucionalização da RMPA e a gestão metropolitana ver o trabalho de Koch e Cortes (2015).
} 
Ao mesmo tempo, verificamos a presença de diversas associações de municípios (algumas incluindo municípios não-metropolitanos na sua composição) atuantes na RMPA. Embora representem uma forma de organização e de articulação "pela base", evidencia-se certa fragmentação regional, exemplificada pela existência de cinco associações de prefeituras na região, sendo a Associação dos Municípios da Região Metropolitana de Porto Alegre (GRANPAL), com treze municípios, e a Associação dos Municípios do Vale do Rio dos Sinos (AMVRS), com nove municípios (e mais três que não fazem parte da RMPA), as principais. Contudo, essas associações cumpriram (e ainda cumprem) o papel de representação dos executivos municipais em muitas decisões metropolitanas.

A fragmentação institucional de municípios é acompanhada pela fragmentação da representação eleitoral da RMPA. Ela está concentrada em poucos candidatos, os quais se situam distantes da temática metropolitana. O comportamento eleitoral da região metropolitana, mais uma vez, confirma as desigualdades socioespaciais da região. Os setores com disputa eleitoral altamente concentrada (de tipo localista) correspondem, em grande medida, aos espaços periféricos da região, enquanto que as áreas de dispersão alta (com representação mais universalista) estão circunscritas à Porto Alegre, o município polo da região (Fedozzi e Correa, 2015). A fragmentação da representação política metropolitana fortalece as conexões políticas de tipo localista e paroquial, o que desestimula a introdução dos temas de natureza metropolitana no debate. Ao longo do tempo, esse padrão espacial de representação tem contribuído para o fracionamento político do espaço metropolitano e, por consequência, para impor obstáculos a uma gestão real do território metropolitano (Idem, 2015). É importante ter em conta que, no período analisado (1980-2010), também ocorreram reestruturações políticas, especialmente após 1988, com a descentralização administrativa e, a partir de 2003, um maior pro- 
tagonismo do papel do Estado na gestão econômica e social. Saliente-se, ainda, que vivemos um período inédito de valorização da participação democrática da sociedade civil, via conselhos e conferências que exigem a representação da sociedade em diversos níveis e esferas de governo no país. Mas esse processo não inclui, até hoje, o nível regional metropolitano dos estados da Federação.

Ainda sobre a Região Metropolitana de Porto Alegre, é importante apontar que, entre 2010 e 2014, a postura do governo do Rio Grande do Sul com relação à RMPA favoreceu a implementação de instâncias próprias de gestão da metrópole. Entre elas, a criação da Câmara Técnica do Desenvolvimento Metropolitano (2011), no âmbito do Conselho de Desenvolvimento Econômico e Social (CDES-RS) e a instituição do Conselho Metropolitano dos Municípios (CDM), em 2012. Em 2015, foi criado o Parlamento Metropolitano, composto pelas Câmaras de Vereadores dos municípios da RMPA, o que já significa maior percepção de setores políticos locais sobre importância da questão metropolitana.

A promulgação, em 2015, do Estatuto da Metrópole, representa um momento inédito pós-redemocratização de reconhecimento nacional da importância de gestão das regiões metropolitanas. A lei federal estabelece diretrizes gerais para o planejamento, a gestão e a execução das funções públicas de interesse comum nas regiões metropolitanas brasileiras, bem como normas gerais sobre os instrumentos de "governança interfederativa" e os critérios para o apoio da União às ações que envolvam o desenvolvimento urbano e sustentável dessas regiões. O Estatuto da Metrópole prevê ainda a instituição de um "Plano de Desenvolvimento Urbano Integrado" para as regiões metropolitanas institucionalizadas pelos estados, que deverá realizar o planejamento dos espaços e a compatibilização territorial das políticas públicas no âmbito dos municípios metropolitanos. 
O Estatuto prevê, ainda, "a participação de representantes da sociedade civil nos processos de planejamento e de tomada de decisão, no acompanhamento da prestação de serviços e na realização de obras afetas às funções públicas de interesse comum" nas regiões metropolitanas. Também prevê que, para terem status metropolitano pleno, as regiões metropolitanas devem manter uma estrutura de governança interfederativa de caráter permanente e democrático, além de um corpo técnico responsável pelo planejamento e implementação das políticas públicas (Estatuto da Metrópole, 2015).

Com esses novos instrumentos legais, cabe aos atores políticos empenharem-se para que a gestão metropolitana participativa avance na RMPA, espaço que requer uma gestão apropriada para enfrentar os desafios da sua organização econômica, social e territorial.

\section{Considerações finais}

A Região Metropolitana de Porto Alegre configura-se como uma das mais importantes concentrações urbanas e (ainda) industriais do Brasil. Sua presença no território nacional remete ao final dos anos 1960, quando tanto o fenômeno metropolitano já podia ser percebido (com os processos de conurbação e industrialização entre seus diferentes núcleos urbanos, especialmente os mais próximos da capital), como a percepção da necessidade de planejamento das funções metropolitanas, especialmente habitação e transporte. Nesse período e ao longo das décadas de 1970 e 1980, a RMPA caracterizou-se como uma área tipicamente fordista (e terceiro-mundista), com os problemas decorrentes da rápida concentração de população e infraestruturas econômicas e urbanas no território.

A década de 1990 foi de reestruturação neoliberal, cujos efeitos mais visíveis foram o recrudescimento das desigualdades socioespaciais 
intrametropolitanas e o processo de reestruturação econômica, com a crise da indústria e a emergência de uma economia mais alicerçada nos serviços. Essa dualidade favoreceu o núcleo metropolitano, o qual se tornou um espaço mais elitizado, de concentração dos estratos sociais superiores, enquanto que a periferia metropolitana se consolidava como o espaço operário por excelência.

O advento do século XXI trouxe novas mudanças para a RMPA. Uma nova fase "desenvolvimentista" e "liberal-periférica" de crescimento econômico provocou transformações importantes no espaço metropolitano, com a desconcentração metropolitana, o surgimento de novas centralidades, a diversificação social e a configuração de um espaço metropolitano mais heterogêneo, fragmentado e complexo.

Essa nova configuração metropolitana, que corresponde, em parte, às transformações metropolitanas observadas em nível nacional, latino-americano e mundial, impõe novos desafios aos gestores e à sociedade metropolitana. Entretanto, no momento em que a mesma se consolida, temos na atualidade, novamente, um período de crise e recessão econômicas no país, que já está impactando os estratos inferiores da composição social metropolitana. Por outro lado, novos instrumentos institucionais estão disponíveis para que seja implementado um novo modelo de gestão à altura da complexidade dos problemas metropolitanos contemporâneos. Espera-se que os atores sociais da Região Metropolitana se mobilizem em prol da implantação e utilização dos mesmos.

Paulo Roberto Rodrigues Soares: Doutor em Geografia Humana. Professor do Departamento de Geografia e do Programa de Pós-graduação em Geografia da Universidade Federal do Rio Grande do Sul. Membro do Laboratório do Espaço Social (LABES) e pesquisador do Observatório das Metrópoles - Núcleo Porto Alegre. $\triangle$ paulo.soares@ufrgs.br 
Luciano Joel Fedozzi: Doutor em Sociologia. Professor do Departamento de Sociologia e do Programa de Pós-graduação em Sociologia da Universidade Federal do Rio Grande do Sul. Coordenador do Grupo de Pesquisa Democracia Participativa, Esfera Pública e Cidades e pesquisador do Observatório das Metrópoles - Núcleo Porto Alegre. $\$ lucianofedozzi@gmail.com.

\section{Referências}

1. BOITO Jr., A. As bases políticas do neodesenvolvimentismo. Trabalho apresentado no Fórum Econômico da FGV. São Paulo: Fundação Getúlio Vargas, 2012

2. BORSDORF, A. Cómo modelar el desarrollo y la dinámica de la ciudad latinoamericana. EURE (Santiago), vol. 29, n. 86, p. 37-49, 2003

3. CANO, W. Desequilíbrios regionais e concentração industrial no Brasil 1930-1995. São Paulo: Editora da Unesp, 2007

4. CASTELLS, M. La región metropolitana en red como forma urbana de la era de la información. $\tilde{N}$ - Revista de Cultura. Buenos Aires: El Clarín, 28 de junio de 2013. Edición digital disponible en: http://www.revistaenie.clarin.com/ideas/Manuel-Castells-Sociedad-Red-urbanismo_0_946705335.html. Acesso em 26/02/2016.

5. CICCOLELLA, P. Globalización y dualización en la Región Metropolitana de Buenos Aires: Grandes inversiones y reestructuración socioterritorial en los años noventa. EURE (Santiago), vol. 25, no. 76, p. 5-27, 1999

6. FEDOZZI, L.; CORREA, F. S. Conexões eleitorais e geografia social do voto na Região Metropolitana de Porto Alegre: das debilidades da "polity" aos déficits da "policy". In: FEDOZZI, L.; SOARES, P. R. R. (eds.) Porto Alegre: transformações na ordem urbana. Rio de Janeiro: Letra Capital/Observatório das Metrópoles, 2015, p. 254-294.

7. FEDOZZI, L.; SOARES, P. R. R. (eds.) Porto Alegre: transformações na ordem urbana. 1. ed. Rio de Janeiro: Letra Capital/Observatório das Metrópoles, 2015.

8. FURTADO, C. Formação econômica do Brasil. 27ạ ed. São Paulo, Editora Nacional/Publifolha, 2000.

9. HIDALGO, R. Tipologías de expansión metropolitana en Santiago de Chile: precariópolis estatal y privatópolis inmobiliaria. Scripta Nova (Barcelona) Revista electrónica de geografía y ciencias sociales, n. 12, p. 109, 2008. 
10. IBGE. Regiões de Influência das Cidades (REGIC) 2007. Rio de Janeiro: IBGE, 2008.

11. IBGE. Estimativas de População 2015. Rio de Janeiro: IBGE, 2015. Disponível em http://www.ibge.gov.br/home/estatistica/populacao/estimativa2015/estimativa_tcu.sht. Acesso em 26/02/2016.

12. JANOSCHKA, M. El nuevo modelo de la ciudad latinoamericana: fragmentación y privatización. EURE (Santiago), vol.28, no. 85, p. 11-20, dic. 2002,

13. $\mathrm{KOCH}, \mathrm{E} . ;$ Estadual: Região Metropolitana de Porto Alegre. In FEDOZZI, L.; SOARES, P. R. R. (eds.) Porto Alegre: transformações na ordem urbana. Rio de Janeiro: Letra Capital/Observatório das Metrópoles, 2015, p. 314-344.

14. LENCIONI, S. Referências analíticas para a discussão da metamorfose metropolitana contemporânea. In: LENCIONI, S. et al. (Org.). Transformações sócioterritoriais nas metrópoles de Buenos Aires, São Paulo e Santiago. São Paulo: Paim, 2011, p. 51-64.

15. MAMMARELLA, R., PESSOA, M. L., FERREIRA, G. da S. e TARTARUGA, I. G. P. Estrutura social e organização social do território: Região Metropolitana de Porto Alegre - 1980-2010. In FEDOZZI, L. e SOARES, P. R. R. (eds.) Porto Alegre: transformações na ordem urbana. Rio de Janeiro: Letra Capital/Observatório das Metrópoles, 2015, p. 133-184.

16. MATTOS, C. A. de. Modernización capitalista y transformación metropolitana en América Latina: cinco tendencias constitutivas. En: LEMOS, A. I.; ARROYO, M.; SILVEIRA, M. L. América Latina: cidade, campo e turismo. São Paulo: CLACSO - Consejo Latinoamericano de Ciencias Sociales, 2006, p. 41-76.

17. MATTOS, C. A. de. Globalización, negocios inmobiliarios y transformación urbana. Nueva Sociedad. Democracia y Política en América Latina. № 212, p. 82-96, noviembre-diciembre, 2007.

18. MATTOS, C. A. de. Gobernanza neoliberal, financiarización y metamorfosis urbana en el siglo XXI. Santiago de Chile: Instituto de Estudios Urbanos y Territoriales, PUC-Chile, agosto 2014. Disponible en: Centro de Investigaciones de Políticas Públicas y Territorio, CITE, FLACSO. http://cite.flacsoandes.edu.ec/i/ category/financiamiento-de-la-ciudad/.

19. MONTE-MÓR, R. O que é o urbano, no mundo contemporâneo. Belo Horizonte: UFMG/Cedeplar, 2006 (Texto para discussão no 281).

20. MONTEJANO ESCAMILLA, J.A. Nuevos procesos de metropolización del territorio. Espacialidades. Revista de temas contemporáneos sobre lugares, política y cultura. Vol. 3, No. 2, p. 34-66, jul.-dic. 2013. 
21. OLIVEIRA, F. A Economia da Dependência Imperfeita. Rio de Janeiro, Graal, 1977.

22. RAMÍREZ, B.; PRADILLA COBOS, E. (Orgs.), Teoría sobre la ciudad en América Latina. México DF: Universidad Autónoma Metropolitana, 2013

23. REZENDE, F.; LIMA, R. (Orgs.). Rio-São Paulo: cidades mundiais; desafios e oportunidades. Brasília: IPEA, outubro 1999.

24. RIBEIRO, L. C. Q.; SANTOS Jr., O. A. Governança Empreendedorista e Megaeventos Esportivos: reflexões em torno da experiência brasileira. O Social em Questão, Ano XVI, no 29, p. 23-41, 2013.

25. ROLNIK, R. Guerra dos Lugares. A colonização da terra e da moradia na era das finanças. São Paulo: Boitempo, 2015.

26. SAMPAIO Jr., P. de A. Desenvolvimentismo e neodesenvolvimentismo: tragédia e farsa. Serviço Social \& Sociedade, no 212. São Paulo: out-dez 2012, p. 672-688

27. SANTOS, M. A urbanização brasileira. São Paulo: Hucitec, 1993.

28. SANTOS, M.; SILVEIRA, M.L. O Brasil. Território e Sociedade no início do século 21. Rio de Janeiro: Record, 2001.

29. SOARES, P. R. R, Novas territorialidades e novos discursos sobre a dispersão e a concentração urbanas. In: HEIDRICH, A et al. (Org.) A Emergência da Multiterritorialidade. Porto Alegre: Editora da UFRGS, 2008, p. 163-176.

30. SOARES, P.R.R. A Região Metropolitana de Porto Alegre nos (des)caminhos da metropolização brasileira. In: FEDOZZI, L. e SOARES, P. R. R. (eds.) Porto Alegre: transformações na ordem urbana. 1. ed. Rio de Janeiro: Letra Capital/ Observatório das Metrópoles, 2015, pp. 42-72.

31. SOJA, E. Postmetrópolis. Estudios críticos sobre las ciudades y las regiones. Madrid: Traficantes de Sueños, 2008.

32. TORRES, H. da G. et al. Pobreza e espaço: padrões de segregação em São Paulo. Estudos Avançados, São Paulo, v. 17, n. 47, p. 97-128, Abr. 2003.

33. VELTZ. P. Mondialisation, villes et territoires. L'économie d'archipel. Paris: PUF, 1996.

34. VICENTE RUFÍ, J. Nuevas palabras, nuevas ciudades? Revista de Geografia (Barcelona), 2003, no 2, p. 79-103

Recebido em: 30/03/2016

Aceite Final: 02/05/2016 